\title{
Transapical transcatheter aortic valve implantation for predominant aortic regurgitation with a self-expandable valve
}

\author{
Huan Liu", Shun Liu", Yuntao Lu\#, Ye Yang, Wenshuo Wang, Liming Zhu, Lai Wei, Chunsheng Wang \\ Department of Cardiovascular Surgery, Zhongshan Hospital, Shanghai Cardiovascular Institution, Fudan University, Shanghai 200032, China \\ Contributions: (I) Conception and design: All authors; (II) Administrative support: C Wang; (III) Provision of study materials or patients: L Wei, C \\ Wang; (IV) Collection and assembly of data: H Liu, S Liu, Y Yang; (V) Data analysis and interpretation: H Liu, Y Lu, W Wang; (VI) Manuscript \\ writing: All authors; (VII) Final approval of manuscript: All authors. \\ \#These authors contributed equally to this work. \\ Correspondence to: Lai Wei. Department of Cardiovascular Surgery, Zhongshan Hospital, Shanghai Cardiovascular Institution, Fudan University, \\ 1609, Xietu Road, Room 639, Building 16, Shanghai 200032, China. Email: wl_heartsurgeon@126.com.
}

\begin{abstract}
Background: Transcatheter aortic valve implantation (TAVI) has become the gold standard for high-risk severe aortic stenosis. However, the experience of treating aortic regurgitation (AR) with this technology is still limited. Previously, we have demonstrated excellent 1-year outcomes of transapical TAVI with J-Valve ${ }^{\mathrm{TM}}$ (JieCheng Medical Technology Co., Ltd., Suzhou, China) in treating predominant AR, while the mid-term outcomes up to 4 years have never been reported.

Methods: Transapical TAVI with J-Valve ${ }^{\mathrm{TM}}$ to treat predominant AR was performed in 47 patients in Zhongshan Hospital from May 2014 through October 2018. Procedural and clinical outcomes with followup up to 4 years were analyzed using Valve Academic Research Consortium-2 criteria (VARC-2).

Results: All patients (age 73.7 \pm 7.9 years) were considered to be prohibitive or high-risk for surgical aortic valve replacement (SAVR) (logistic European System for Cardiac Operative Risk Evaluation, 21.1\% to $44.4 \%$; mean, $24.3 \% \pm 5.1 \%$ ) after evaluated by a multidisciplinary heart team. Transapical implantations were successful in all patients. The clinical outcomes of the entire cohort in the latest follow-up (371 to 1,968 days, median 574 days) included all-cause mortality (6.4\%), disabling stroke (2.3\%), new permanent pacemaker (6.8\%) and valve-related re-intervention (0). Paravalvular leak (PVL) was rate as none or trace in 37 of 44 and mild in 7 of 44 patients at the latest follow-up. Mean transvalvular gradient was favorable after valve implantation during follow-up at $9.3 \pm 2.5 \mathrm{mmHg}$.

Conclusions: This study revealed that, transapical TAVI with J-Valve ${ }^{\mathrm{TM}}$ for treating AR has encouraging mid-term outcomes, and the advantages at one year demonstrated in previous study can be maintained through 4 years.
\end{abstract}

Keywords: Transcatheter aortic valve implantation (TAVI); aortic valve insufficiency; heart valve prosthesis

Submitted Nov 07, 2019. Accepted for publication Dec 24, 2019.

doi: $10.21037 /$ jtd.2020.01.04

View this article at: http://dx.doi.org/10.21037/jtd.2020.01.04

\section{Introduction}

Transcatheter aortic valve implantation (TAVI) has become a standard treatment for patients with severe symptomatic aortic stenosis at increased or prohibitive surgical risk (1-3). Early outcomes of TAVI in intermediate-risk patients were proven to be not inferior or even superior to surgical aortic valve replacement (SAVR) in recent randomized trials (4-7). With improvements in technology and surgical technique, the indication for TAVI is still expanding, including predominant aortic regurgitation (AR), degenerated bioprosthetic valve, bicuspid aortic valve, and more (8). However, the experience of TAVI in treating predominant AR is still limited. A few previous studies have showed the 


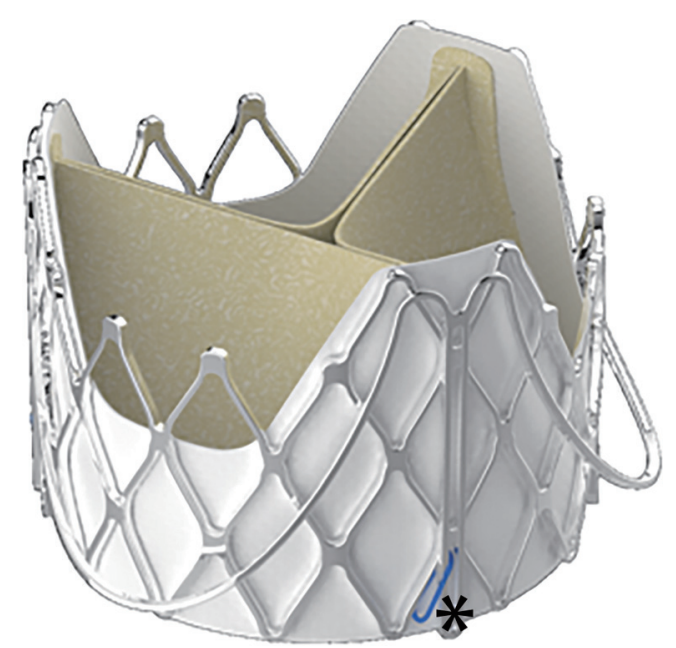

Figure 1 Schematic drawing of the J-Valve ${ }^{\mathrm{TM}}$ device. The movable connection between the clasper and the frame relies on a suture between them.

feasibility and promising early outcomes of this technology with different devices (9-16). The mid-term outcomes have never been reported.

We started our TAVI for AR program in May 2014 with a novel self-expandable device-J-Valve ${ }^{\mathrm{TM}}$ (JieCheng Medical Technology Co., Ltd., Suzhou, China) (Figure 1). The feasibility study and one-year outcomes have been reported in our previous publications $(9,10)$. Compared to early studies with other devices, these studies demonstrated excellent short-term outcomes, demonstrating higher procedural successful rate, lower mortality, lower rate of permanent pacemaker and second valve implantation, as well as less paravalvular leak (PVL). Forty-seven patients with predominant AR were treated with transapical TAVI in our institute from May 2014 through October 2018. All patients were followed periodically. Procedural results and clinical outcomes up to 4 years were analyzed using Valve Academic Research Consortium 2 criteria (17).

\section{Methods}

\section{Study population and preoperative evaluation}

From May 2014 through October 2018, 47 patients with predominant AR were enrolled for transapical implantation of J-Valve ${ }^{\mathrm{TM}}$ in Zhongshan Hospital, Fudan University. The entire cohort was consisted of two sub-cohorts. The first 16 patients underwent the procedures before August 2015, which is part of the feasibility clinical trial (Registered with the Chinese Clinical Trial Registry, ChiCTROPC-15006354). Another 31 patients underwent the procedures after the device became commercially available after 2017. Two surgeons from our institution performed all of the operations in this series. A multidisciplinary heart team evaluated all patients before admission. Prohibitiverisk was defined as an estimated probability of death or serious irreversible morbidity after SAVR of $>50 \%$. Patients' age $\geq 60$ years and at prohibitive or high-risk, as defined by a logistic EuroSCORE (European System for Cardiac Operative Risk Evaluation) $\geq 20 \%$, were scheduled for TAVI. The addition of specific clinical and anatomic variables that might affect mortality (18), such as frailty, major organ system compromise, and procedurespecific impediment including severe aortic calcification, inflammatory aortitis were routinely considered in decisionmaking.

A routine workup with transthoracic echocardiography (TTE) and contrast enhanced multidetector computed tomography (MDCT) was performed. Patients with an aortic sinus or ascending aorta diameter $>50 \mathrm{~mm}$ or an annulus diameter $>29 \mathrm{~mm}$ was excluded in preliminary stage of this study since the maximum size of the prosthesis was $27 \mathrm{~mm}$ during that time. After the $29 \mathrm{~mm}$ prosthesis was available since 2017, only annulus diameter over $31 \mathrm{~mm}$ was excluded. Coronary ostia height $<10 \mathrm{~mm}$ was not considered a contraindication to this procedure. The details of both clinical and morphology evaluations with MDCT have been described in our previous study (9).

\section{Procedural techniques}

The procedures were performed in hybrid operating room under general anesthesia with single-lumen endotracheal intubations. Transesophageal echocardiography (TEE) was routinely performed to evaluate the morphology of the aortic root and monitor the whole process of valve positioning and deployment. TEE was paramount in confirming proper descent of the three claspers into the nadirs of the sinuses during the positioning process. TEE was used to monitor coaxiality during prosthesis deployment and delivery system withdrawal. A balloontipped bipolar endocardial temporary pacing catheter (St. Jude Medical, St. Paul, Minnesota) was routinely inserted through internal jugular vein or femoral vein into the apex of the right ventricle. The cardiopulmonary bypass was available on standby in the early stage of our program. TTE was performed to determine the position of the left 


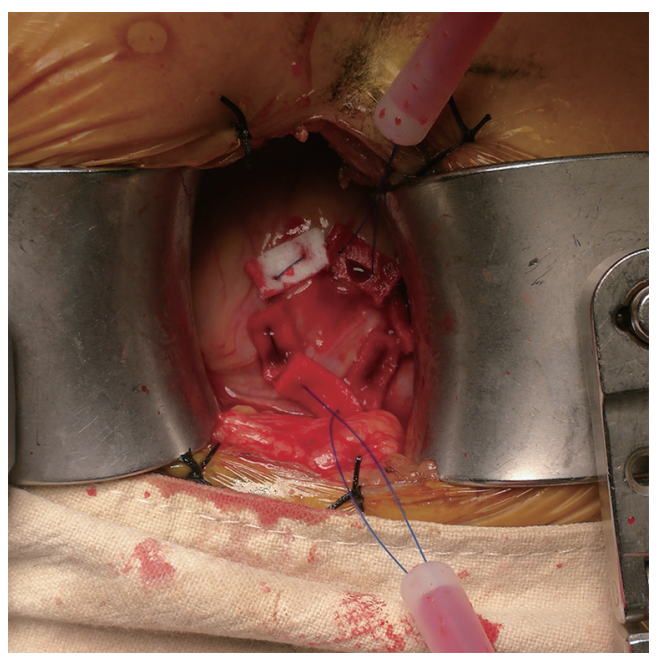

Figure 2 Two purse-string sutures were made on the left ventricle apex as hexagonal shapes.

ventricular apex and the aortic valve, which helped the surgeon to choose the optimal intercostal space incision and direction for advancing the delivery system.

After draping, a 5-F sheath was inserted in the common femoral artery with Seldinger technique. Angiogram was performed by injection of the contrast through the side branch of the sheath to make sure there was no vascular complication at this moment. A limited left thoracotomy (6 to $8 \mathrm{~cm}$ long) was made over the optimal intercostal space. Two purse-string sutures were made on the left ventricle apex as hexagonal shapes (Figure 2). The patient was then heparinized with $1 \mathrm{mg} / \mathrm{kg}$ heparin. The $\mathrm{C}$-arm was set at the optimal angle followed by insertion of a pigtail catheter (OptiMed, Etlingen, Germany), which was positioned into one of the aortic sinuses (most commonly the right coronary sinus). The primary aortic root angiogram was performed.

A standard polytetrafluoroethylene-coated EMERALD guidewire (Cordis Johnson \& Johnson, Miami Lakes, Florida) was inserted through the ventricle apex and advanced into the descending aortic with the guidance of a right Judkins catheter (Cordis Johnson \& Johnson). A series of dilators were used to pre-dilate the puncture site to accommodate the delivery system. The size of the delivery sheath was $27-\mathrm{F}$ for prosthesis of size 23,25 and $27 \mathrm{~mm}$, 31-F for size $29 \mathrm{~mm}$. No apical sheath was utilized in any case. The delivery system was inserted into the left ventricle and across the aortic valve. The implantation process was consisted of two stages including positioning the clasper as well as lowering and deployment of the prosthesis. There was no need for annulus dilation or rapid pacing. The detail of the implantation process was described in our previous studies $(9,10)$.

After the prosthesis was released, both the delivery system and the guidewire were withdrawn. Protamine of $1.5 \mathrm{mg} / \mathrm{kg}$ was administrated and hemostasis was achieved. Both TEE and the final root angiogram were performed to evaluate the function of the prosthesis and degree of PVL. In most cases, angiograms were performed for three times (each time with $20 \mathrm{ml}$ of Iohexol injection): at the beginning of the operation, before valve deployed, after valve deployed. In some cases, the fourth angiogram was needed to verify improvement of PVL after administration of protamine. The incision was closed in routine fashion with a 24-F chest tube inserted. The patient was administrated daily warfarin to keep the international normalized ratio between 2.0 to 3.0 for 6 months.

\section{Data collection}

All relevant baseline, procedural, and follow-up data were prospectively collected. The demographical characteristics including age, gender and BMI were collected, the related medical history including smoking, hypertension, diabetes, peripheral vascular disease, etc. were collected. The key parameters of echocardiography and MDCT were all collected. The classification of acute kidney injury (AKI) was defined according to previous publications (19).

\section{Follow-up}

Clinical and transthoracic echocardiographic examinations were performed before discharge and at 30 days, 6 months, 1 year and each year after the procedure. The entire cohort had been follow-up for at least 1-year. Sixteen out of 47 patients, who were enrolled in the feasibility clinical trial, had a follow-up period up to 4 years. Outcomes were analyzed in accordance with the updated standardized endpoints defined by the Valve Academic Research Consortium-2 (17).

\section{Ethics}

The feasibility clinical trial part of the study was approved by the Chinese Food and Drug Administration (CFDA) and registered with the Chinese Clinical Trial Registry (ChiCTR-OPC-15006354). These patients provided 
Table 1 Demographics and baseline clinical parameters

\begin{tabular}{|c|c|}
\hline Parameters & Value \\
\hline Age, years & $73.7 \pm 7.9$ \\
\hline Male & $34(72.3)$ \\
\hline BMI, $\mathrm{kg} / \mathrm{m}^{2}$ & $22.6 \pm 2.9$ \\
\hline Smoking & $8(17.0)$ \\
\hline Systemic hypertension & $31(66.0)$ \\
\hline Diabetes mellitus & $4(8.5)$ \\
\hline Hyperlipidemia & 7 (14.9) \\
\hline Peripheral vascular disease & $10(21.3)$ \\
\hline Cerebrovascular disease & $15(31.9)$ \\
\hline Previous stroke & $3(6.4)$ \\
\hline Atrial fibrillation & $9(19.1)$ \\
\hline Chronic lung disease & $9(19.1)$ \\
\hline Serum creatinine, $\mathrm{mg} / \mathrm{dL}$ & $1.1 \pm 0.4$ \\
\hline Anemia & $18(38.3)$ \\
\hline Coronary artery disease & $11(23.4)$ \\
\hline Recent myocardial infarction within 30 days & 0 \\
\hline Previous coronary artery bypass graft & $2(4.3)$ \\
\hline Previous valve surgery & $1(2.1)$ \\
\hline NYHA functional class > III & $35(74.5)$ \\
\hline Ascending aortic diameter, $\mathrm{mm}$ & $40.1 \pm 4.9$ \\
\hline \multicolumn{2}{|l|}{ Etiology } \\
\hline Degenerative & $42(89.4)$ \\
\hline Bicuspid & $3(6.4)$ \\
\hline Inflammatory aortitis & $2(4.3)$ \\
\hline \multicolumn{2}{|l|}{ Aortic regurgitation grade } \\
\hline None or mild & 0 \\
\hline Moderate & 0 \\
\hline Severe & $47(100.0)$ \\
\hline Aortic $\mathrm{V}_{\max }, \mathrm{m} / \mathrm{s}$ & $1.4 \pm 0.7$ \\
\hline Aortic mean $\Delta \mathrm{P}, \mathrm{mmHg}$ & $5.4 \pm 4.4$ \\
\hline $\mathrm{MR} \geq$ moderate & $5(10.6)$ \\
\hline LVEF, \% & $52.3 \pm 12.4$ \\
\hline LVEDD, mm & $59.2 \pm 8.4$ \\
\hline Log ES, \% & $24.3 \pm 5.1$ \\
\hline
\end{tabular}

Values are mean \pm SD or $\mathrm{n}(\%)$. BMI, body mass index; LVEF, left ventricular ejection fraction; log ES, logistic European System for Cardiac Operative Risk Evaluation (EuroSCORE); LVEDD, left ventricular end-diastolic diameter; MR, mitral regurgitation; NYHA, New York Heart Association functional class; $\Delta P$, pressure gradient; $\mathrm{V}_{\max }$, maximum aortic velocity. signed written consent. The research in patients enrolled after the device commercially available was approved by IRB with patient consent waived. All patients were fully informed about the procedure. The local Ethics Committees and Institutional Review Board (IRB) approved the study protocol in accordance with the principles of the Declaration of Helsinki.

\section{Statistic analysis}

Normally distributed continuous variables are presented as mean \pm standard deviation; non-normally distributed variables, as median and range; and categorical variables, as number and percentage. Survival was investigated using Kaplan-Meier analysis. All statistical analyses were performed with SAS version 9.2 (SAS Institute, Cary, NC).

\section{Results}

\section{Demographical and baseline characteristics}

Detailed baseline patient characteristics are found in Table 1 . All of 47 patients had severe AR with symptoms of left ventricular dysfunction. Three patients had congenital bicuspid aortic valve. According to the definition in recent guidelines, five patients had mild aortic stenosis, and the other 42 patients had no aortic stenosis. No case had significant aortic valve calcification defined as any voxel above 130 Hounsfield units in non-contrast enhanced MDCT. One patient had history of permanent pacemaker implantation while no other patients had preoperative second-degree or higher degree of atrioventricular block (AVB). Two patients had history of coronary artery bypass and one patient had a degenerated freestyle aortic root bioprosthesis. Two patients had history of percutaneous coronary intervention. All patients were evaluated by interdisciplinary heart team and deemed to be at prohibitive or high-risk for SAVR. The mean logistic EuroSCORE [European System for Cardiac Operative Risk Evaluation] was $24.3 \% \pm 5.1 \%$.

\section{Procedural outcomes}

Procedural outcomes and valve function data immediate after implantation are found in Table 2. No patient was converted to SAVR. All cases were performed without cardiopulmonary bypass. No rapid pacing was necessary. No pre or post balloon dilation was needed in any case. One 
Table 2 Procedure Outcomes and Detailed Valve Function Immediate After Implantation

\begin{tabular}{|c|c|}
\hline Parameters & $\mathrm{N}=47$ \\
\hline \multicolumn{2}{|l|}{ Aortic annulus diameter } \\
\hline TTE, mm & $23.3 \pm 2.0$ \\
\hline MDCT perimeter-derived, $\mathrm{mm}$ & $27.1 \pm 2.2$ \\
\hline MDCT area-derived, $\mathrm{mm}$ & $25.3 \pm 1.9$ \\
\hline MDCT STJ diameter, mm & $36.5 \pm 4.9$ \\
\hline MDCT LCA ostium height, $\mathrm{mm}$ & $13.1 \pm 3.7$ \\
\hline MDCT RCA ostium height, mm & $17.4 \pm 5.5$ \\
\hline Contrast agent, mL & $72.2 \pm 13.7$ \\
\hline Successful implantation & $47(100.0)$ \\
\hline Conversion to SAVR & 0 \\
\hline \multicolumn{2}{|l|}{ THV size, mm } \\
\hline 23 & $1(2.1)$ \\
\hline 25 & $7(14.9)$ \\
\hline 27 & $26(55.3)$ \\
\hline 29 & $13(27.7)$ \\
\hline \multicolumn{2}{|l|}{ "Oversize" strategy } \\
\hline Based on TTE & $16.00 \%(-4.17 \%$ to $42.11 \%)$ \\
\hline $\begin{array}{l}\text { Based on MDCT perimeter- } \\
\text { derived }\end{array}$ & $0.93 \%(-11.59 \%$ to $7.53 \%)$ \\
\hline Based on MDCT area-derived & $7.82 \%(-4.59 \%$ to $18.91 \%)$ \\
\hline Post-dilation & 0 \\
\hline Second valve implantation & $1(2.1)$ \\
\hline Combined $\mathrm{PCl}$ & 0 \\
\hline Coronary obstruction & 0 \\
\hline Annulus rupture & 0 \\
\hline Transfusion & $2(4.3)$ \\
\hline \multicolumn{2}{|l|}{ Paravalvular aortic regurgitation } \\
\hline None & $20(42.6)$ \\
\hline Trace & $16(34.0)$ \\
\hline Mild & $10(21.3)$ \\
\hline Moderate & $1(2.1)$ \\
\hline \multicolumn{2}{|l|}{ Intravalvular regurgitation } \\
\hline None & $27(57.4)$ \\
\hline Trace & $20(42.6)$ \\
\hline $\begin{array}{l}\text { Mean aortic valve gradient, } \\
\mathrm{mmHg}\end{array}$ & $5.3 \pm 2.8$ \\
\hline
\end{tabular}

Values are mean \pm SD or $\mathrm{n}(\%)$ or median (minimal to maximum). LCA, left coronary artery; MDCT, multidetector computed tomography; $\mathrm{PCl}$, percutaneous coronary intervention; RCA, right coronary artery; SAVR, surgical aortic valve replacement; STJ, sinotubular junction; TTE, transthoracic echocardiography. patient had a second valve implanted after the prosthesis migrated to the arch. No third-degree AVB, myocardium infarction or cerebrovascular events occurred during the procedures.

Hemostasis was easily achieved in all cases. Two patients had intraoperative transfusion. Function of the prosthesis was assessed immediately after implantation by TEE and angiogram. There was no significant intravalvular regurgitation or stenosis of the prosthesis. One patient had moderate PVL; the other patients had PVL no more than mild degree.

\section{Clinical outcomes and follow-up}

Detailed clinical outcomes at the 30-day, 6-month, 1-year and the latest follow-up are presented in Table 3. The median follow-up time was 574 days (range, 371-1,968 days). Sixteen out of 47 patients were enrolled in the feasibility clinical trial. They underwent the procedures before August 2015. Fifteen out 16 patients survived to the 4 -year followup. The outcomes of these patients from 2-year through 4-year were listed separately in Table 4.

One patient with moderate PVL died of low cardiac output 25 days after the operation. The patient had a bicuspid aortic valve and was in New York Heart Association (NYHA) grade IV before the operation. Another two patients suffered from sudden deaths at home without clear diagnosis during the follow-up (643 and 823 days after surgery respectively). In the entire cohort, 44 patients survived to the latest follow-up, including 2 patients (4.5\%) in NYHA functional class III and 42 patients $(95.5 \%)$ in NYHA class I or II. All patients had significant improve in symptoms of exertional dyspnea and exercise intolerance. The 1- and 4-year survivals free from all-cause mortality were $97.9 \%$ and $86.4 \%$ respectively based on Kaplan-Meier analysis (Figure 3). There was no patient in the cohort need a valve-related re-intervention during the entire follow-up.

No patient experienced myocardial infarction or any vascular complications during the follow-up. No neurological complications including transient ischemic attack or stroke occurred during the hospital stay. One patient experienced cerebral hemorrhage at 20 months after the procedure. No patient experienced major bleeding during or after the procedure. Two patients required blood transfusion during the hospital stay. According to the Acute Kidney Injury Network classification (19), 8 patients had stage 1 AKI while no patient need hemodialysis after the procedure. 
Table 3 Clinical endpoints of the entire cohort

\begin{tabular}{|c|c|c|c|c|}
\hline Endpoints & 30-day & 6-month & 1-year & Latest follow-up ( $371-1,968$ days, median 574 days) \\
\hline Patients at risk & 47 & 46 & 46 & 44 \\
\hline Myocardial infarction & 0 & 0 & 0 & 0 \\
\hline \multicolumn{5}{|c|}{ Stroke or transient ischemic attack } \\
\hline Transient ischemia attack & 0 & 0 & 0 & 0 \\
\hline Bleeding complications & 0 & 0 & 0 & 0 \\
\hline \multicolumn{5}{|l|}{ Acute kidney injury } \\
\hline Stage 1 & $8(17.0)$ & $8(17.4)$ & $8(17.4)$ & $8(18.2)$ \\
\hline Permanent pacemaker & $2(4.3)$ & $3(6.5)$ & $3(6.5)$ & $3(6.8)$ \\
\hline Coronary obstruction & 0 & 0 & 0 & 0 \\
\hline Valve-related re-intervention & 0 & 0 & 0 & 0 \\
\hline
\end{tabular}

Table 4 Clinical endpoints of patients in feasibility clinical trial with follow-up over 4 years $(\mathrm{N}=16)$

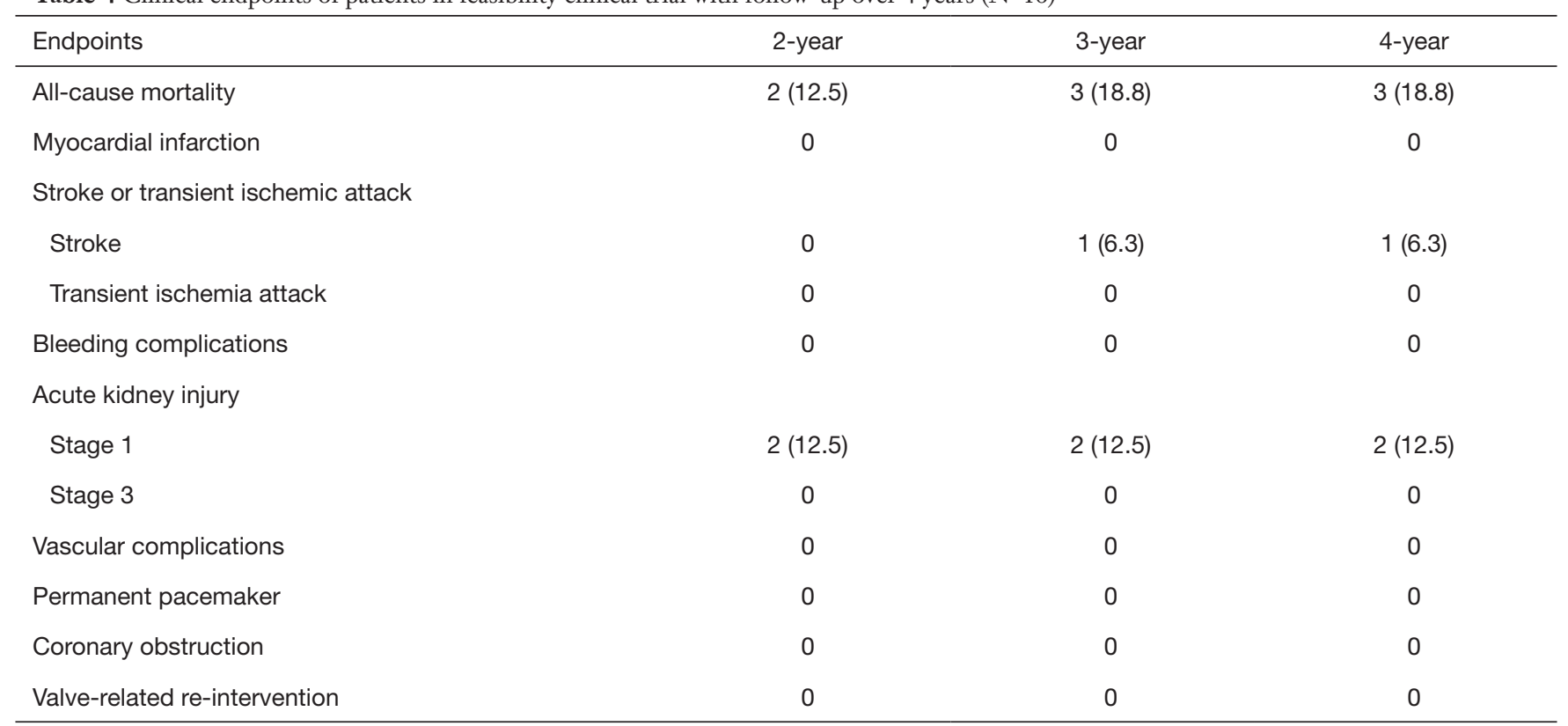

Values are $\mathrm{n}(\%)$.

Two patients developed third-degree AVB within 1 week after the procedure. Another patient had third-degree $\mathrm{AVB}$ at 2 months after the procedure. All of these patients received permanent pacemakers. Another two patients developed first-degree AVB during the hospital stay and recovered shortly after discharge. Nine patients had left 


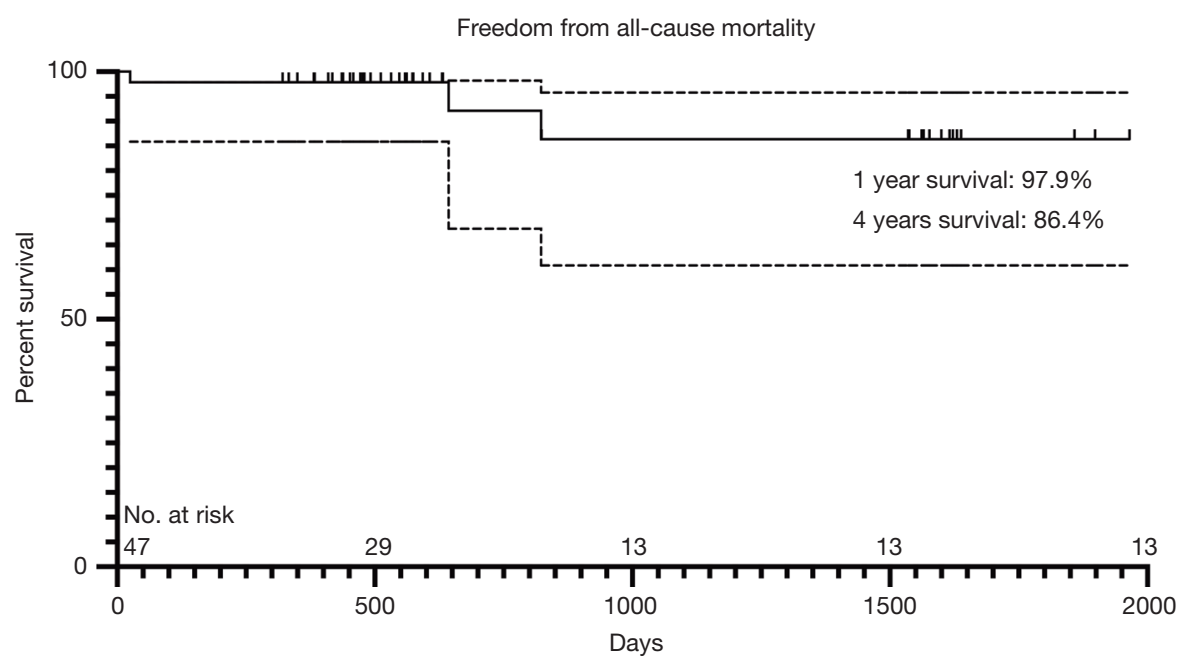

Figure 3 Kaplan-Meier estimation of freedom from all-cause mortality.

bundle branch block after the procedure while three patients had right bundle branch block. No patient developed a new arrhythmia resulting in hemodynamic instability during hospital stay and follow-up. No complications associated with incisions occurred.

\section{Echocardiography findings}

Results of follow-up echocardiography are summarized in Table 5. Echocardiography was performed before discharge, 1, 6 and 12 months and yearly thereafter surgery. The degree of AR in baseline and the PVL during follow-up are shown in Figure 4.

\section{Discussion}

Since the first 'proof-of-concept' case of TAVI was reported by Cribier and colleagues in 2002 (20), it has been rapidly evolving during the last 17 years. To date, over 300,000 TAVIs have been performed worldwide (21). TAVI has emerged as a standard treatment for patients with symptomatic severe aortic stenosis who deemed to be at high or prohibitive risk for SAVR (22). As iterations of the devices as well as technique improvement, more data are emerging to show the efficacy of TAVI in expanded indications including bicuspid aortic valve disease, pure AR, degenerated surgical bioprosthesis. In the meantime, TAVI has been proven to be a valid alternative to SAVR in patients at intermediate surgical risk. And the role of TAVI in low risk patients is still being evaluated.
Although experience of TAVI for AR is still limited, several previous studies had reported the off-label use of TAVI for non-calcified pure AR with a wide spectrum of devices $(9,11,13-15,23-26)$. The procedure and early outcomes in these studies varied significantly from each other. Given the anatomical differences between aortic stenosis and regurgitation, first-generation devices, which were designed for severe calcified stenotic valves, faced a great challenge in treating non-calcified pure AR. The absence of calcified orifice, dilated root and annulus resulted in high incidence of valve migration, need for second valve implantation and PVL more than moderate degree in the early studies.

The most important modification in second-generation devices is the introduction of self-positioning clasper or feeler $(10,13)$. This smart design could help to precisely position the prosthesis as well as enhance the anchoring power. These features play an important role in overcoming the technical difficulties in treating AR. As a result, the outcomes of second-generation devices improved significantly (27).

$\mathrm{J}-\mathrm{Valve}^{\mathrm{TM}}$ is one of the second-generation devices, which differs from other devices though a unique movable connection between the clasper and the frame (Figure 1). We have reported the feasibility study and 1-year outcomes of this device in previous publications, which showed extremely low mortality and morbidity $(9,10)$. However, the mid-term follow-up of this device has never been reported. Herein, we report our single institution experience of a 47 -patient cohort. To our knowledge, it is the largest cohort 
Table 5 Results of echocardiography during follow-up

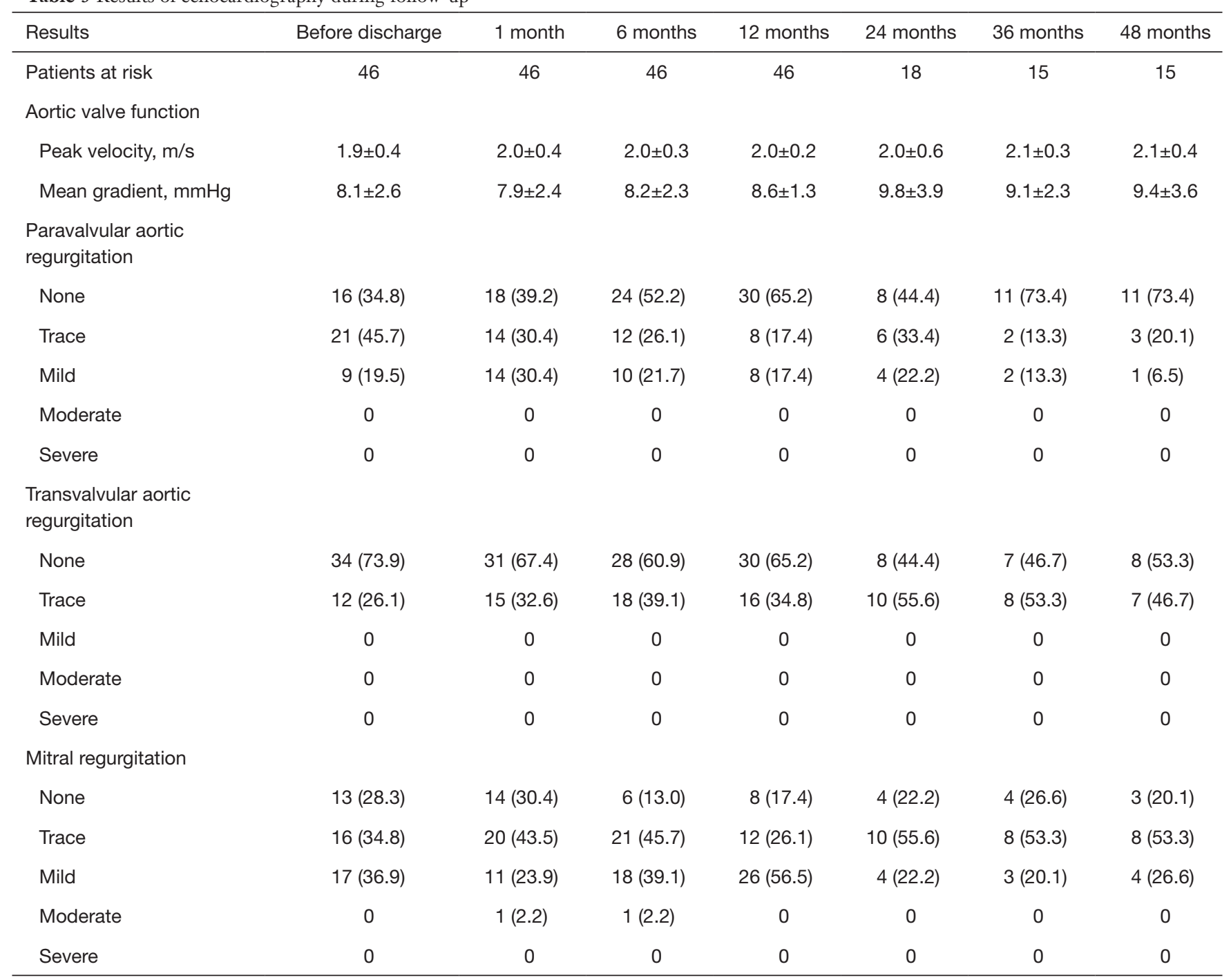

Values are mean \pm SD or $n(\%)$.

ever been reported in TAVI for AR.

Implantations were successful in all cases. According to previous systemic review, the device success rate was $81.1 \%$ for new-generation devices versus $61.3 \%$ for earlygeneration devices (16), while the device success rate of J-Valve ${ }^{\mathrm{TM}}$ in previous reports was $91-100 \%(9,10,25)$. The movable connection between the clasper and frame made the device could be positioned more precisely with a more stable anchoring. The procedure was straightforward with a steep learning curve. The failed implantations were almost related to technique failure in early stage of $\mathrm{J}$-Valve ${ }^{\mathrm{TM}}$ program. We believed that, the successful rate could be even higher in well-selected future cases.
Only one patient $(2.1 \%)$ needed a second valve implantation after the primary valve migrated into the arch. In this case, the perimeter-derived diameter of the annulus was $27.7 \mathrm{~mm}$ in MDCT. We implanted a 29-mm prosthesis. Due to hemodynamic compromise, the valve was deployed quickly in an inappropriate level and result in a migration. After the hemodynamic was stabilized, another $29 \mathrm{~mm}$ was implanted successfully. The rate of need for second valve implantation, which was used to treat PVL after suboptimal positioning, is significant lower than other devices (16.6\%) in previous study (16). The clasper in J-Valve ${ }^{\mathrm{TM}}$ can help in self-positioning and enhancing anchoring, which reduce PVL dramatically. 
Baseline aortic regurgitation and paravalvular regurgitation after TAVI

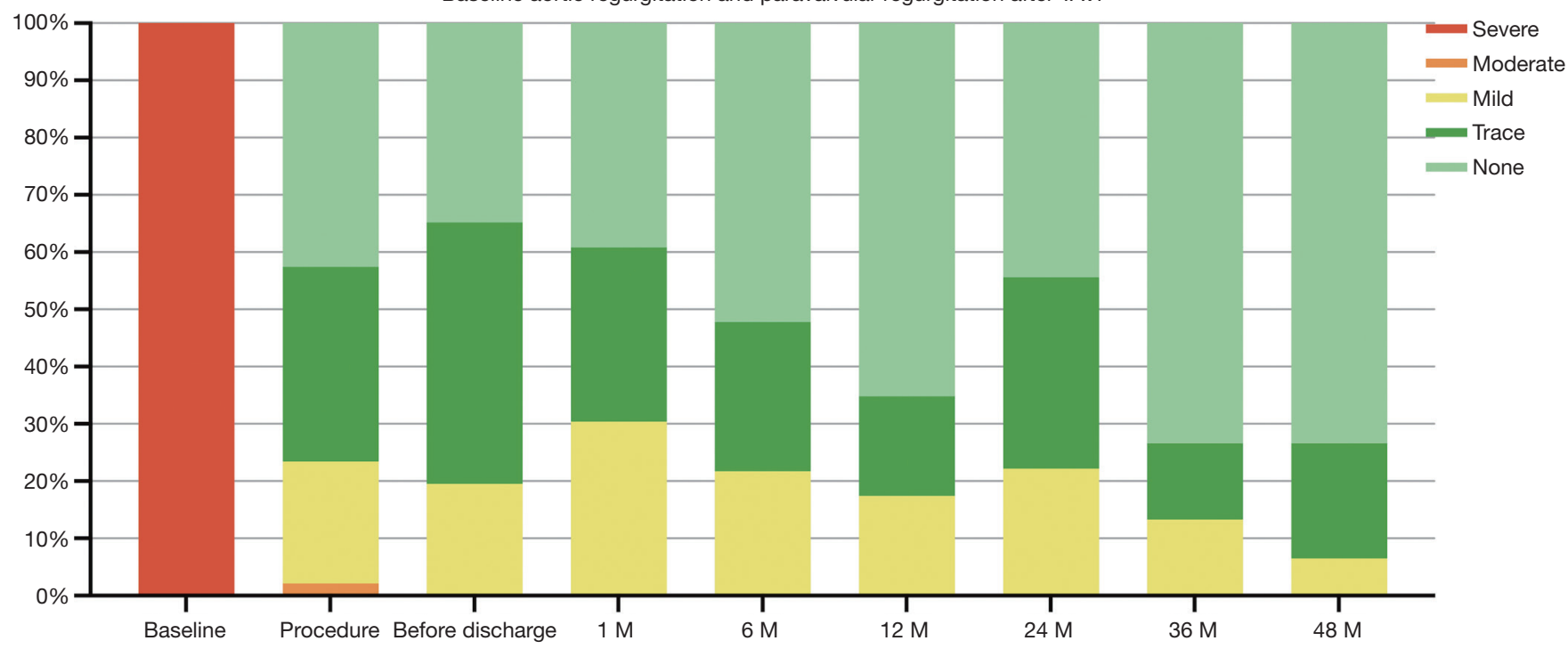

Figure 4 Aortic regurgitation at baseline and paravalvular leak after J-Valve ${ }^{\mathrm{TM}}$ implantation.

The strategy for valve size selection is critical to reduce complications. We analyzed three variables to help decision-making: MDCT perimeter-derived, MDCT areaderived and TTE measured annulus diameters (Table 2). As native annulus is oval shaped, TTE diameter measured from a single plane has the greatest deviation. Given the irregular shape of the native annulus, the perimeter-derived diameter is always larger than the area-derived one. The flexible native annulus will tend to become regular round shaped under the expanding power from the prosthesis, and this round shape will have the same perimeter as we've measured. As a result, it is a wise choice to use MDCT perimeter-derived diameter as a reference. The "oversize" rate in this cohort was between $-11.5 \%$ and $7.53 \%$, the median rate was $0.93 \%$ (Table 2). This result can be interpreted as no "oversize" in majority cases. We believe selecting the size equal to MDCT perimeter-derived diameter is a safe strategy with $\mathrm{J}$-Valve ${ }^{\mathrm{TM}}$ in treating noncalcified AR.

Three patients $(6.8 \%)$ in this cohort needed a new permanent pacemaker, which was much lower than previous report for both early $(17.5 \%)$ and new $(18.6 \%)$ generation devices (16). We believe that the lower rate of permanent pacemaker is related to no "oversize" strategy. Twelve (27.3\%) patients had either left or right bundle branch block in the latest follow-up, however, patients could tolerate quiet well with these conduction disturbances.

In this cohort, there were three cases of bicuspid aortic valve and two cases of inflammatory aortitis. AR with bicuspid morphology without calcification could be carefully selected as candidate for TAVI based on our previous study (10). AR complicated with inflammatory aortitis was a new expanded indication in our practice. SAVR in this subset of patients has a high incidence of PVL. And the severe calcified aorta would make open surgery even more technique challenging and risky. TAVI for patients in this population might be a reasonable alternative. Our two patients did well in the operations, and had no PVL in their recent 1-year follow-up.

A low position of the coronary ostia (less than $10 \mathrm{~mm}$ ) has been highlighted as one of the most important factors contributing to coronary obstruction (28-30). The most frequent mechanism associated with coronary obstruction after TAVI was believed to be the displacement of the calcified native cusp over the coronary ostium. In this cohort, there were ten patients with left coronary ostium height less than $10 \mathrm{~mm}$ and three patients with right coronary ostium height less than $10 \mathrm{~mm}$. However, no coronary obstruction occurred in the entire cohort. With $\mathrm{J}$-Valve ${ }^{\mathrm{TM}}$, the clasper and the prosthesis frame would clip and embrace the native cusps after valve deployed, which protect the coronary ostia from being occluded.

There were three patients had moderate mitral regurgitation (MR) and two had severe MR at baseline. All these MRs were diagnosed to be functional as a result of left ventricle remodeling. All these MRs improved significantly 
in the latest follow-up (no more than mild degree). This indicated that the functional MR over moderate degree associated with severe AR might be improved after successful TAVI.

AR is relatively a benign disease as compared with AS, the long-term durability of the prosthesis turns out to be an important concern. Although very little is known about longterm valve durability after TAVI, $91 \%$ of patients remained free of structural valve deterioration (SVD) between 5 and 10 years post-implantation in a recent study (31). In our TAVI program, over $160 \mathrm{~J}$-valve ${ }^{\mathrm{TM}}$ had been implanted since May 2014, no SVD had occurred so far.

One patient $(2.1 \%)$ died in hospital. The patient had a type-0 bicuspid aortic valve with preoperative hemodynamic compromise. A salvage surgery was performed. The patient had moderate PVL due to suboptimal positioning of the prosthesis. It resulted in low cardiac output and multiorgan dysfunction. She died 25 days after the procedure. There were two patients died suddenly at home at 21 and 27 months after surgery respectively during the follow-up without any definite diagnosis. Given there was no evidence of any significant cardiac structure anomaly or conduction disturbance, cerebral vascular accident might be the etiology upon most occasions. The overall in-hospital mortality is similar as compared with other devices (3.0\%) (16).

This study has several limitations. It was a single institutional nonrandomized observational study without a control group. Only 47 patients were enrolled. The followup period of some patients was less than 2 years. Future randomized studies with more cases, longer follow-up, and control groups for comparisons with conservative treatment and SAVR are needed.

\section{Conclusions}

Transapical TAVI with J-Valve ${ }^{\mathrm{TM}}$ to treat high-risk predominant AR is a safe and effective technique. This technique might be a reasonable alternative to treat patients with special features like inflammatory aortitis and low coronary ostium. J-Valve ${ }^{\mathrm{TM}}$ might have a reasonable longterm durability, which needs to be confirmed in further study.

\section{Acknowledgments}

We thank Dr. Anthony Zaki MD and Dr. Emídio Germano da Silva Neto MD from Department of Thoracic and Cardiovascular Surgery in Cleveland Clinic, Ohio, USA for their language revision for this manuscript.

Funding: This work was supported by National Natural Science Foundation of China Youth Science Foundation Project [81801743]; Shanghai Health and Family Planning Commission Youth Foundation Project [20184Y0162]; and Special Research Fund for Clinical Research of Zhongshan Hospital affiliated to Fudan University [2016ZSLC22].

\section{Footnote}

Conflicts of Interest: The authors have no conflicts of interest to declare.

Ethical Statement: The authors are accountable for all aspects of the work in ensuring that questions related to the accuracy or integrity of any part of the work are appropriately investigated and resolved. All patients were fully informed about the procedure. The local Ethics Committees and Institutional Review Board (IRB) approved the study protocol in accordance with the principles of the Declaration of Helsinki.

Open Access Statement: This is an Open Access article distributed in accordance with the Creative Commons Attribution-NonCommercial-NoDerivs 4.0 International License (CC BY-NC-ND 4.0), which permits the noncommercial replication and distribution of the article with the strict proviso that no changes or edits are made and the original work is properly cited (including links to both the formal publication through the relevant DOI and the license). See: https://creativecommons.org/licenses/by-nc-nd/4.0/.

\section{References}

1. Mack MJ, Leon MB, Smith CR, et al. 5-year outcomes of transcatheter aortic valve replacement or surgical aortic valve replacement for high surgical risk patients with aortic stenosis (PARTNER 1): a randomised controlled trial. Lancet 2015;385:2477-84.

2. Kapadia SR, Leon MB, Makkar RR, et al. 5-year outcomes of transcatheter aortic valve replacement compared with standard treatment for patients with inoperable aortic stenosis (PARTNER 1): a randomised controlled trial. Lancet 2015;385:2485-91.

3. Deeb GM, Reardon MJ, Chetcuti S, et al. 3-year outcomes in high-risk patients who underwent surgical or transcatheter aortic valve replacement. J Am Coll Cardiol 2016;67:2565-74. 
4. Reardon MJ, Van Mieghem NM, Popma JJ, et al. Surgical or Transcatheter Aortic-Valve Replacement in IntermediateRisk Patients. N Engl J Med 2017;376:1321-31.

5. Thyregod HG, Steinbruchel DA, Ihlemann N, et al. Transcatheter Versus Surgical Aortic Valve Replacement in Patients With Severe Aortic Valve Stenosis: 1-Year Results From the All-Comers NOTION Randomized Clinical Trial. J Am Coll Cardiol 2015;65:2184-94.

6. Leon MB, Smith CR, Mack MJ, et al. Transcatheter or Surgical Aortic-Valve Replacement in Intermediate-Risk Patients. N Engl J Med 2016;374:1609-20.

7. Thourani VH, Kodali S, Makkar RR, et al. Transcatheter aortic valve replacement versus surgical valve replacement in intermediate-risk patients: a propensity score analysis. Lancet 2016;387:2218-25.

8. Praz F, Windecker S, Huber C, et al. Expanding Indications of Transcatheter Heart Valve Interventions. JACC Cardiovasc Interv 2015;8:1777-96.

9. Wei L, Liu H, Zhu L, et al. A New Transcatheter Aortic Valve Replacement System for Predominant Aortic Regurgitation Implantation of the J-Valve and Early Outcome. JACC Cardiovasc Interv 2015;8:1831-41.

10. Liu H, Yang Y, Wang W, et al. Transapical transcatheter aortic valve replacement for aortic regurgitation with a second-generation heart valve. J Thorac Cardiovasc Surg 2018;156:106-16.

11. Testa L, Latib A, Rossi ML, et al. CoreValve implantation for severe aortic regurgitation: a multicentre registry. EuroIntervention 2014;10:739-45.

12. Schlingloff F, Schafer U, Frerker C, et al. Transcatheter aortic valve implantation of a second-generation valve for pure aortic regurgitation: procedural outcome, haemodynamic data and follow-up. Interact Cardiovasc Thorac Surg 2014;19:388-93.

13. Seiffert M, Bader R, Kappert U, et al. Initial German experience with transapical implantation of a secondgeneration transcatheter heart valve for the treatment of aortic regurgitation. JACC Cardiovasc Interv 2014;7:1168-74.

14. Wendt D, Kahlert P, Pasa S, et al. Transapical transcatheter aortic valve for severe aortic regurgitation: expanding the limits. JACC Cardiovasc Interv 2014;7:1159-67.

15. Schofer J, Nietlispach F, Bijuklic K, et al. Transfemoral Implantation of a Fully Repositionable and Retrievable Transcatheter Valve for Noncalcified Pure Aortic Regurgitation. JACC Cardiovasc Interv 2015;8:1842-9.

16. Yoon SH, Schmidt T, Bleiziffer S, et al. Transcatheter Aortic Valve Replacement in Pure Native Aortic Valve
Regurgitation. J Am Coll Cardiol 2017;70:2752-63.

17. Kappetein AP, Head SJ, Genereux P, et al. Updated standardized endpoint definitions for transcatheter aortic valve implantation: the Valve Academic Research Consortium-2 consensus document. J Am Coll Cardiol 2012;60:1438-54.

18. Rosenhek R, Iung B, Tornos P, et al. ESC Working Group on Valvular Heart Disease Position Paper: assessing the risk of interventions in patients with valvular heart disease. Eur Heart J 2012;33:822-8, 828a, 828b.

19. Mehta RL, Kellum JA, Shah SV, et al. Acute Kidney Injury Network: report of an initiative to improve outcomes in acute kidney injury. Crit Care 2007;11:R31.

20. Cribier A, Eltchaninoff H, Bash A, et al. Percutaneous transcatheter implantation of an aortic valve prosthesis for calcific aortic stenosis: first human case description. Circulation 2002;106:3006-8.

21. Puri R, Chamandi C, Rodriguez-Gabella T, et al. Future of transcatheter aortic valve implantation - evolving clinical indications. Nat Rev Cardiol 2018;15:57-65.

22. Nishimura RA, Otto CM, Bonow RO, et al. 2017 AHA/ ACC Focused Update of the 2014 AHA/ACC Guideline for the Management of Patients With Valvular Heart Disease: A Report of the American College of Cardiology/ American Heart Association Task Force on Clinical Practice Guidelines. J Am Coll Cardiol 2017;70:252-89.

23. Frerker C, Schewel J, Schewel D, et al. Expansion of the indication of transcatheter aortic valve implantation--feasibility and outcome in "off-label" patients compared with "on-label" patients. J Invasive Cardiol 2015;27:229-36.

24. Roy DA, Schaefer U, Guetta V, et al. Transcatheter aortic valve implantation for pure severe native aortic valve regurgitation. Journal of the American College of Cardiology 2013;61:1577-84.

25. Zhu D, Chen Y, Guo Y, et al. Transapical transcatheter aortic valve implantation using a new second-generation TAVI system-J-Valve ${ }^{\mathrm{TM}}$ for high-risk patients with aortic valve diseases: Initial results with 90-day follow-up. International journal of cardiology 2015;199:155-62.

26. Koschyk D, Seiffert M, Conradi L, et al. Transcatheter Aortic Valve Implantation for non-calcified pure aortic insufficiency-initial results and follow-up. Catheterization and Cardiovascular Interventions 2014;83:S211-S2.

27. Franzone A, Piccolo R, Siontis GC, et al. Transcatheter aortic valve replacement for the treatment of pure native aortic valve regurgitation: a systematic review. JACC Cardiovasc Interv 2016;9:2308-17. 
28. Ribeiro HB, Sarmento-Leite R, Siqueira DA, et al. Coronary obstruction following transcatheter aortic valve implantation. Arq Bras Cardiol 2014;102:93-6.

29. Holmes DR Jr, Mack MJ, Kaul S, et al. 2012 ACCF/AATS/ SCAI/STS expert consensus document on transcatheter aortic valve replacement: developed in collaboration with the American Heart Association, American Society of Echocardiography, European Association for Cardio-Thoracic Surgery, Heart Failure Society of America, Mended Hearts, Society of Cardiovascular

Cite this article as: Liu H, Liu S, Lu Y, Yang Y, Wang W, Zhu L, Wei L, Wang C. Transapical transcatheter aortic valve implantation for predominant aortic regurgitation with a self-expandable valve. J Thorac Dis 2020;12(3):538-549. doi: $10.21037 /$ jtd.2020.01.04
Anesthesiologists, Society of Cardiovascular Computed Tomography, and Society for Cardiovascular Magnetic Resonance. J Thorac Cardiovasc Surg 2012;144:e29-84.

30. Masson JB, Kovac J, Schuler G, et al. Transcatheter aortic valve implantation: review of the nature, management, and avoidance of procedural complications. JACC Cardiovasc Interv 2009;2:811-20.

31. Blackman DJ, Saraf S, MacCarthy PA, et al. Long-Term Durability of Transcatheter Aortic Valve Prostheses. J Am Coll Cardiol 2019;73:537-45. 